InternationalTinnitusJournal.2018;22(2):160-169.

\title{
Otolaryngologic Symptoms in Multiple Sclerosis: A Review
}

\author{
Massimo Ralli ${ }^{1}$ \\ Arianna Di Stadio 2 \\ Irene Claudia Visconti \\ Francesca Yoshie Russo ${ }^{1}$ \\ Maria Patrizia Orlando ${ }^{1}$ \\ Maria Paola Balla ${ }^{4}$ \\ Antonio Greco ${ }^{1}$ \\ Marco de Vincentiis ${ }^{3}$
}

\begin{abstract}
Many symptoms of multiple sclerosis may affect the ear, nose and throat. The most common otolaryngologic symptoms of multiple sclerosis are speech disorders, followed by sleep disorders, vertigo and disequilibrium, dysphagia, smell alterations, and hearing loss. Less common symptoms include sialorrhea, facial palsy, taste alterations, trigeminal neuralgia and tinnitus. The origin of otolaryngologic symptoms in multiple sclerosis is mainly central, although increasing evidence also suggests a peripheral involvement.

Otolaryngologic symptoms in multiple sclerosis may have different clinical presentations; they can appear in different stages of the pathology, in some cases they can be the presenting symptoms and their worsening may be correlated with reactivation of the disease. Many of these symptoms significantly affect the quality of life or patients and lead to increased morbidity and mortality.

Otolaryngologic symptoms are common in multiple sclerosis; however, they are often overlooked. In many cases, they follow the relapsing-remitting phases of the disease, and may spontaneously disappear, leading to a delay in multiple sclerosis diagnosis. Clinicians should be aware of otolaryngologic symptoms of multiple sclerosis, especially when they are associated to neurologic symptoms, as they may be early signs of a still undiagnosed multiple sclerosis or could help monitor disease progression in already diagnosed patients.
\end{abstract}

Keywords: otolaryngologic symptoms, demyelination, multiple sclerosis, otolaryngology, MRI.

${ }^{1}$ Department of Sense Organs, Sapienza University of Rome, Rome, Italy

2Department of Otolaryngology, University of Perugia, Italy

${ }^{3}$ Department of Odontostomatology and Maxillofacial Sciences, Sapienza University of Rome, Rome, Italy

${ }^{4}$ Department of Anatomy, Histology, Legal Medicine and Orthopaedics, Sapienza University of Rome, Italy

Send correspondence to:

Arianna Di Stadio

Department of Otolaryngology, University of Perugia, Perugia, Italy. E-mail: ariannadistadio@hotmail.com 


\section{INTRODUCTION}

Multiple Sclerosis (MS) is an autoimmune-mediated neurodegenerative demyelinating disease characterized by relapsing and remitting phases with invalidating longterm sequelae especially in late-diagnosed cases ${ }^{1}$. MS is one of the most common neurodegenerative diseases with a prevalence that vary with geography and ethnicity ranging from 2 per 100.000 in Japan to more than 100 per 100.000 in Northern Europe and North America². MS has a strong gender effect, with prevalence in women almost double compared to men².

The etiology and pathogenesis of MS remains unclear ${ }^{3-5}$; it may be correlated to genetic predisposition ${ }^{6}$, to environmental factors and food habits ${ }^{7}$, and to the action of viruses that induce the expression of recessive genotypes $^{8}$. Any of these may induce an altered autoimmune response of the central nervous system that leads to destruction of myelin associated with activated microglia ${ }^{9,10}$. Microglia, a cell population that belongs to the macrophage family, can change its phenotype by passing from an aggressive-demyelinating form (M1) to a protective-demyelinating form (M2) ${ }^{9,10}$. The alternation between these two forms is modulated by several factors ${ }^{10}$ and may explain the temporariness of many MS symptoms and their natural regression. However, besides the presence of microglia at sites of demyelination, its role in the pathogenesis of MS is only beginning to be revealed ${ }^{9}$.

MS clinical presentation and progression are characterized by high variability and diversity ${ }^{11}$. Common symptoms include weakness or numbness in one or more limbs, optic neuritis, tremor and ataxic gait from cerebellar dysfunction, double vision, dysarthria, or dizziness and fatigue $^{12}$. Most symptoms have an acute onset; however, the pattern of presentation can be highly variable, and symptoms may fluctuate considerably or even progress in correlation with the relapsing/remitting phases of the disease ${ }^{10,12}$

Many symptoms of MS may affect the ear, nose and throat. They include hearing loss, tinnitus, vertigo and disequilibrium, facial palsy, dysphonia, dysphagia, sialorrhea, trigeminal neuralgia and neuropathy, sleep disorder and taste and smell alterations. The prevalence of otolaryngologic symptoms in patients with MS may significantly vary; they present in different stages of the pathology (early- or late-MS) and their worsening may be correlated with the reactivation of $\mathrm{MS}^{1,10}$. Prevalence of the otolaryngologic symptoms that may present in patients with MS is detailed in Table 1.

The origin of otolaryngologic symptoms in MS is mainly central, although increasing evidence also suggests a peripheral involvement5,9,13,14. O'Malley et al. studied the temporal bones of patients with systemic auto-immune diseases and Sensorineural Hearing Loss (SNHL) or vertigo and identified microglia in the inner ear ${ }^{15}$; however,
Table 1. Prevalence of the otolaryngologic symptoms that may present in patients with MS.

\begin{tabular}{lc}
\hline \multicolumn{1}{c}{ Otolaryngologic symptom } & $\begin{array}{c}\text { Prevalence in multiple } \\
\text { sclerosis }\end{array}$ \\
\hline Dysphonia & $44 \%-70 \%$ \\
Dysarthria & $40 \%-62 \%$ \\
Sleep Disorders & $25 \%-54 \%$ \\
Vertigo & $20 \%-35 \%$ \\
Dysphagia & $24 \%-37 \%$ \\
Smell alterations & $15 \%-23 \%$ \\
Hearing loss & $0.7 \%-25 \%$ \\
Sialorrhea & $5 \%-10 \%$ \\
Facial palsy & $7 \%$ \\
Taste alterations & $<5 \%$ \\
Trigeminal neuralgia-sensory neuropathy & $0.3 \%-2 \%$ \\
Tinnitus & $1 \%$ \\
\hline
\end{tabular}

the specific phenotype was not identified. Other authors have shown that microglia can migrate from the brain to the close neural structures ${ }^{14,16}$ following inflammation. It can be therefore speculated that microglia could migrate through the internal auditory canal reaching the cochlea and determining the demyelination of inner ear structures such as hair cells and spiral ganglion ${ }^{14}$. The possible migration of microglia to the periphery may determine not only audio-vestibular symptoms, but also other otolaryngologic symptoms (Figure 1).

Otolaryngologic symptoms, as many others in MS, tend to be transient and regress spontaneously. Most of them, especially when the exact pathogenesis is unclear, are treated during the acute phase with corticosteroids. Steroids, thanks to their combined immune-suppressant/ anti-inflammatory activity, can rapidly resolve the symptoms, but may also lead to a delay in the diagnosis of MS.

The high variability of presentation and different characteristics of otolaryngologic symptoms often lead to a delay in the definite diagnosis of MS. The aim of this review is to describe and discuss current evidences and highlight recent findings of the otolaryngologic symptoms of MS.

\section{OTOLARYNGOLOGIC SYMPTOMS IN MULTIPLE SCLEROSIS}

\section{Hearing loss and tinnitus}

Several studies have documented the relationship between MS and hearing loss and tinnitus ${ }^{16-20}$. Hearing deficits in MS present in the form of sudden, progressive or fluctuating SNHL they may appear in the early stages of the disease, often as presenting symptoms, or during the late stages indicating a disease progression as a result of a progressive involvement of the hearing pathways ${ }^{17,19,20}$.

Sudden SNHL is more common in the early stages (within two years from diagnosis), while progressive SNHL in late stages (after five years) ${ }^{16-20}$. Often, hearing loss can fluctuate; this may be related to relapsing/remitting 


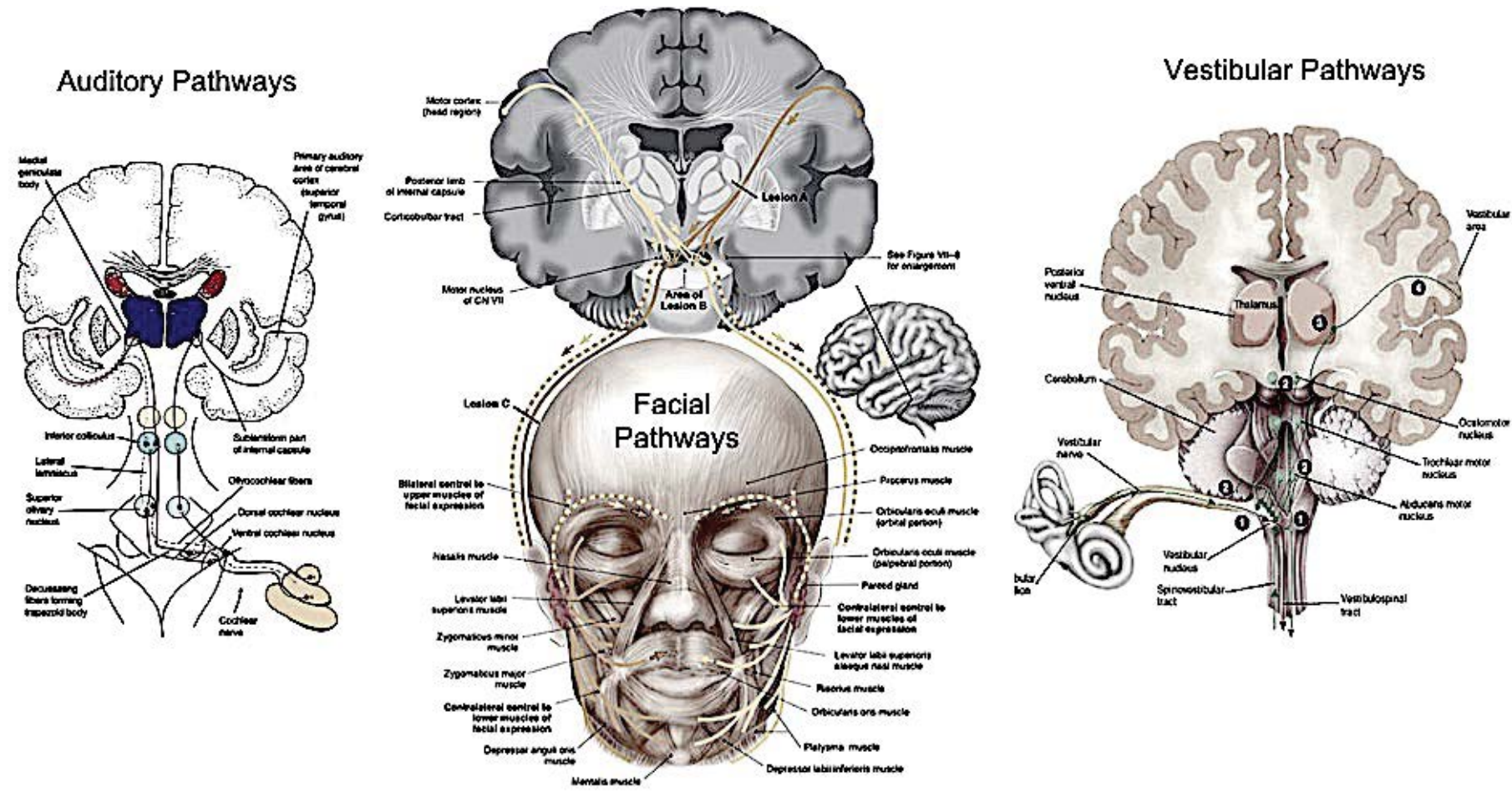

Figure 1. The image shows the auditory, facial and vestibular pathways. Lesions in pons, medulla and brainstem located in one or more area of these pathways may generate a symptom. Multiple symptoms can be observed especially in the late stages of multiple sclerosis, due to the dissemination of demyelinating lesions.

phases that occur during the course of MS or to the use of corticosteroids which are able to fight the systemic inflammation generated by MS. In many cases, even in the presence of lesions in the auditory pathways at Magnetic Resonance Imaging (MRI), there are no clinically evident hearing deficits ${ }^{19}$.

The origin of SNHL in MS can be central or peripheral, following demyelination of central or peripheral audiovestibular pathways that acts as an "on-off" mechanism; some authors have observed patients with hearing deficit and altered electrophysiologic responses indicative of demyelination without evidence of lesions at MRI ${ }^{17}$.

Hearing loss may be a presenting symptom of $\mathrm{MS}^{21}$; however, although its importance as an early symptom of MS has been described by many studies, its significance is largely underestimated. This may be due to its temporary nature and the good response to corticosteroid treatment; in fact, nearly $90 \%$ of patients with sudden SNHL are given an initial diagnosis of "idiopathic" sudden $\mathrm{SNHL}^{22}$.

Tinnitus, the perception of a sound when no external stimulation is present ${ }^{23}$, is commonly found in patients with hearing loss following presbycusis 24,25 , noise exposure ${ }^{26,27}$ or other auditory conditions ${ }^{28,29}$; however, it can also be found in patients with a clinically normal hearing, following synaptopathy ${ }^{30,31}$, somatic disorders ${ }^{32-37}$ and psychological dysfunctions ${ }^{38}$.

Tinnitus has been described in many autoimmune conditions ${ }^{39}$; in patients with MS it may follow SNHL or derive from central nervous system demyelination, especially in cases in which no auditory alterations are evident ${ }^{18,40}$.

Audiological investigations as tonal and speech audiometry, Auditory Brainstem Responses (ABR), and transient (TEOAE) or Distortion Product Otoacoustic Emissions (DPOAE) are crucial to correctly describe and characterize hearing deficits in patients with MS. Often, clinical audiometry is not able to detect deficits in MS patients possibly due to forms of hidden hearing loss $^{30,31,40}$, and ABR is necessary ${ }^{16}$. A recent review of the literature that included 47 studies and 1533 patients evaluated, among other tests, the role of ABR in MS patients, showing that it was abnormal in the majority of MS patients during the active phase and remained altered in nearly $1 / 4$ of the patients even after complete hearing recovery occurred ${ }^{16}$. ABR has an elevate sensitivity and specificity for the detection of demyelination in the auditory pathways of patients with MS. In fact, the increased latencies in the conduction of the auditory impulse and the absence of wave $V$ can be signs of central alteration ${ }^{41}$. Speech audiometry is particularly important to highlight the difficulty in speech perception-especially in noise ${ }^{42}$ that is common in MS patients following abnormal auditory processing ${ }^{43}$ or cognitive deficit that altered the word recognition ability ${ }^{44}$. In addition, attention and auditory discrimination, which are crucial aspects in binaural perception and in the integration of sounds, can be compromised in MS patient ${ }^{43}$. TEOAE and DPOAE 
may identify damages in specific areas of the cochlea sustained by a peripheral microglia aggression; however, so far their use has been always associated with $A B R$ in clinical studies ${ }^{45}$ because the evidence on the cochlea involvement in MS is still unclear.

SNHL should be always considered in the differential diagnosis of MS, especially in young subjects without a history of hearing impairment ${ }^{16}$. Otolaryngologists should always consider the possibility that SNHL, especially in its sudden form, may be an early symptom of MS.

\section{Vertigo and Disequilibrium}

Vertigo and disequilibrium are common symptoms in $\mathrm{MS}^{46,47}$. The origin of vertigo can be peripheral, following the involvement of the cochlea ${ }^{48}$, or-mainly-central, due to demyelinating lesions affecting the vestibular pathways such as the vestibular nuclei ${ }^{46}$. In some cases, it may follow the involvement of both the cochlea and the vestibular pathways. The origin of vertigo and disequilibrium in MS patients is more often attributed to stiffness, musculoskeletal weakness and ocular diseases rather than to the involvement of the vestibular pathways and of the inner ear ${ }^{47,49}$.

The electrophysiologic investigation with Vestibular Evoked Myogenic Potential (VEMP) has been recently proposed to identify areas of demyelination in the vestibular pathways of MS patients ${ }^{50}$. Furthermore, cervical-VEMPs can exclude the ocular involvement that may modify the sensitivity of VEMPs by interfering with the vestibular responses through ocular fixation compensation by allowing identification of the specific areas affected from demyelination ${ }^{51}$.

The study of nystagmus with Frenzel goggles allows the identification of nystagmus characteristics as direction, latency, adaptation and fatigue. Patients with MS typically present a multidirectional nystagmus without latency 52 ; this may contribute to differential diagnosis by excluding other condition such as vestibular neuritis, Ménière Disease and benign positional paroxysmal vertigo ${ }^{48,53,54}$. Electronystagmography can be used in differential diagnosis to correctly identify which area (brain, pons, medulla o cerebellum) is affected from the demyelination.

\section{Facial Palsy}

Facial palsy may be found in MS patients ${ }^{55}$, sometimes as a presenting symptom ${ }^{56,57}$. Facial palsy may follow a lesion in the central facial pathways, including the motor cortex or the facial nuclei ${ }^{58}$ or be due to a peripheral involvement of the facial nerve following a progressive demyelization of the peripheral axon ${ }^{55}$.

In both cases, a facial palsy with the typical characteristic of a peripheral facial paralysis may be the onset symptom of $\mathrm{MS}^{30-32}$. Usually, facial palsy may involve all muscle of the hemiface similar to a Bell's palsy ${ }^{58,59}$ by meaning that the demyelinating lesions are distributed in both brain hemisphere and in particular in the area of motor cortex with involvement of posterior limb of internal capsule and the corticobulbar tract (Figure 2) ${ }^{58}$.

In case of peripheral involvement of the facial pathways, the lesion is commonly located in the Roof Entry Zone ${ }^{60}$, consistently with the theory of microglia migration?.

Differential diagnosis with MS in cases of facial palsy is of paramount importance to avoid a delay in MS diagnosis. Due to the rarity of the peripheral involvement (facial nerve outside the stylomastoid foramen), an Electromyography may be not useful for a correct diagnosing a MS-related facial palsy. MS should be considered when there's no improvement after corticosteroid therapy or in case
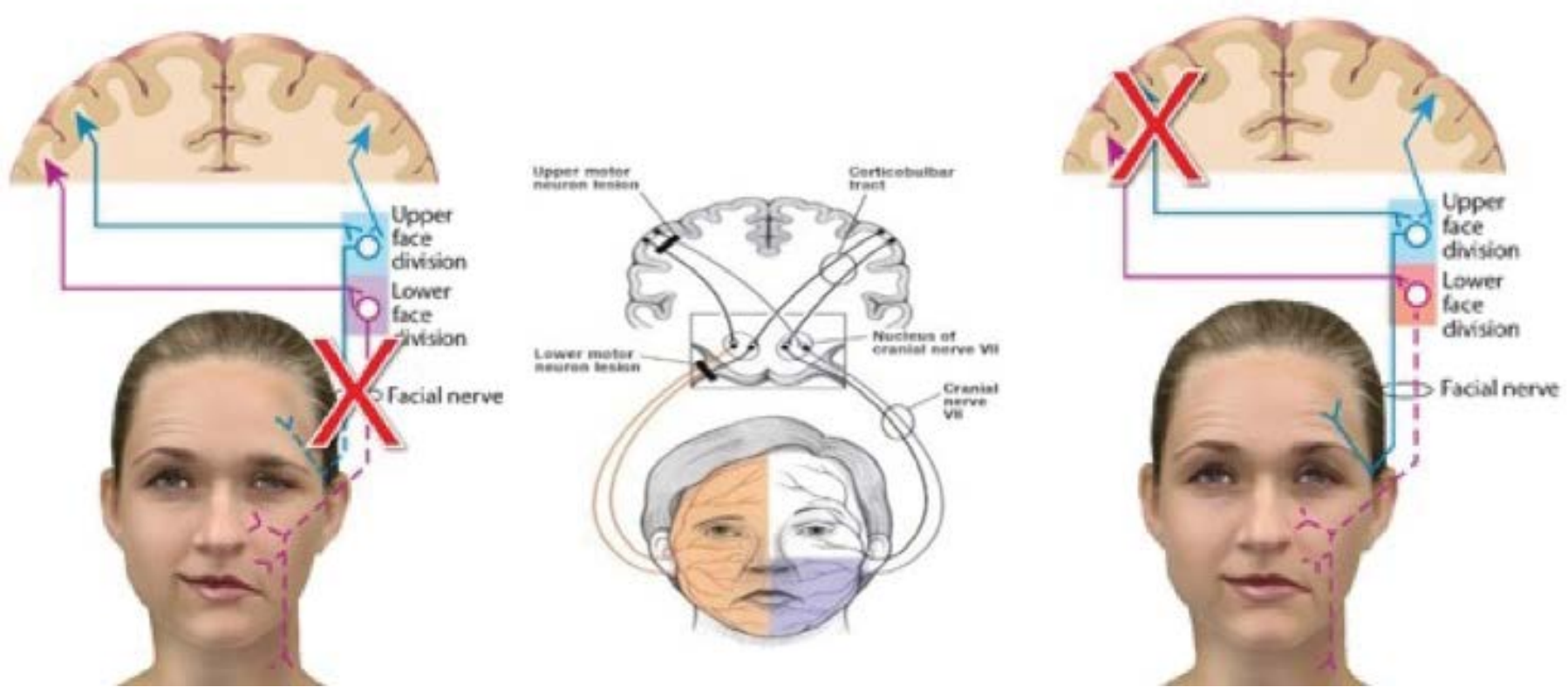

Figure 2. The image shows the facial pathways. Facial palsy will assume the typical aspect of a peripheral form due to the spread of demyelinating lesion in both brain hemispheres; if the lesion is instead in a single hemisphere the palsy will have the typical aspect of a central form. 
of short term recurrence; in these cases second-level investigations such as MRI to identify the demyelinating lesions should be performed ${ }^{61,62}$.

\section{Trigeminal Neuralgia and Trigeminal Sensory Neuropathy}

Maxillofacial manifestations such as trigeminal neuralgia and trigeminal sensory neuropathy have been reported in $\mathrm{MS}^{63}$.

Trigeminal neuralgia has been reported in MS with prevalence near $2 \%$ of cases ${ }^{64}$; it usually appears after the diagnosis of MS has been made although it can be the first manifestation of the disease in $0.3 \%$ of cases ${ }^{65}$. Trigeminal neuralgia in MS is characterized by paroxysmal severe pain that only lasts for a few seconds; however, it can return multiple times during the day ${ }^{66}$. Curiously, Hartman et al. observed that in MS the trigeminal neuralgia may be triggered by an auditory stimulus ${ }^{67}$.

Sensory neuropathy in MS is often bilateral, progressive and irreversible, with a sudden and often painful onset. It mainly affects the second and third divisions of the trigeminal nerve ${ }^{68}$. Neuropathy of the mental nerve causes numbness of the lower lip and chin, with or without pain ${ }^{69}$.

The origin of trigeminal symptoms in MS is commonly a central lesion in the trigeminal nuclei or in the more superior trigeminal pathway ${ }^{70}$; Nakashima et al. showed that women affected from MS and trigeminal disorders presented demyelinating lesions in the linear pontine trigeminal $\operatorname{root}^{71}$.

The trigeminal nerve function can be investigated using electrophysiologic tests ${ }^{72}$; the most common finding in MS is the presence of electrophysiologic impairment with increased amplitudes and delayed latencies.

Trigeminal neuralgia in MS may be treated pharmacologically; botulin toxin injection may be helpful to alleviate pain. Surgery should be avoided because it does not offer long term relief ( $<2$ years) in patients with $\mathrm{MS}^{73}$.

\section{Smell alterations}

Smell alterations may be present in MS with a prevalence ranging from $15 \%$ to $45 \%{ }^{74-79}$ and are mainly described during the active phases of the disease. Olfactory disorders in MS often begins with an altered perception of smell (dysosmia) that progressively worsen to complete anosmia ${ }^{80,81}$.

The causes of smell alterations in MS can be both peripheral and central demyelination; in the former case, they may be correlated to the damage of the olfactory receptors, while in the latter demyelination plaques that develop in the olfactory bulb or in the cortex-especially the inferior frontal and temporal-lobe regions-may be responsible of the symptoms. In particular, the smell threshold alteration is often associated with a peripheral damage, while odor discrimination is related to a central process $^{75,77,78,82,83}$.

The diagnosis of olfactory alterations can be made using olfactometry $^{84}$, and a worsening of this condition may be an indicator of disease progression due to the increasing of number of lesion or to the extension of demyelinating $\operatorname{areas}^{74,79}$.

\section{Taste alterations}

Taste alterations have been reported in nearly $20 \%$ of MS patients ${ }^{75,80}$, although much controversy still exist on the exact prevalence of this symptom due to its strict correlation with smell ${ }^{80,85}$. Taste alterations may appear as presenting symptoms or later in the progression of the disease, and often have a temporary nature associated to the inflammatory phases of MS. Current evidence suggest a central origin of these alterations ${ }^{85,86}$; in particular, transitory taste alterations may follow demyelination in the lateral part of midpontine tegmentum, while in case of a persistent symptom, the demyelinating lesions may occupy midbrain or the caudal portion. Clinical evaluation of taste alterations can be done using electrogustometry, chemogustometry and self-administered questionnaires ${ }^{87}$. Electrogustometry may be very useful for diagnosis and monitoring of MS; Sarmiento et al. showed that patients with MS presented increased threshold and difficulties to identify tastants for all four classic taste qualities on both anterior (VII) and posterior regions of the tongue (IX) ${ }^{88}$ and that such difficulties increased with the progression of MS.

\section{Sialorrhoea}

Sialorrhoea and drooling are conditions of hypersalivation ${ }^{89}$ that may be found in many neurodegenerative disorders ${ }^{90}$; in MS they are usually found in the advanced stages of the disease. Sialorrhea is an invalidating condition with serious implications on quality of life ${ }^{91}$. It can be a primary dysfunction of cholinergic signals, characterized by a hyper production of saliva from the major salivary glands, or it could follow an impairment of swallowing coordination ${ }^{90}$.

Both conditions may be related to a central lesion in the superior salivary nuclei for primary forms and in the swallowing pathways for secondary forms. In case of advanced MS stage, multiple lesions and the spread of demyelination plaques in the brain and medulla may explain the presence of sialorrhea

Sialorrhea may be treated with botulin toxin injected in the salivary glands to reduce the salivary production ${ }^{90,92-94}$, with drugs that inhibit saliva production ${ }^{95}$ or with physical rehabilitation to improve the swallowing coordination ${ }^{56}$.

\section{Dysphagia}

Abnormalities of swallowing are commonly encountered in MS, especially in the most disabled patients [96]; dysphagia is a symptom that can be found in 20 to $30 \%$ 
of these patients $[97,98]$. Dysphagia is characterized by the alteration in the progression of the bolus through oropharynx, hypopharynx and esophagus due to a loss of swallowing coordination [98]; muscle stiffness or weakness, difficulties in concentration and expiratory/ inspiratory discoordination may further aggravate the symptom [99]. Dysphagia can rarely be a presenting symptom of MS, while it is more often seen in the late stage of the disease. This may follow the increased number of lesions in the swallowing pathways that impact the esophageal phase (upper oesophageal sphincter dysfunction), the increased stiffness of the tongue (buccal phase), and the worsening of weakness of the mouth and neck muscles (pharyngeal-laringeal phase) that alter the swallowing progression ${ }^{96-99}$.

Videofluoroscopy studies showed that MS patients present swallowing abnormalities such as dysmotility and impaired retraction of the tongue, delay, prolongation or even loss of the pharyngeal phase, upper esophageal sphincter dysfunction, deficit of laryngeal closure, and diminished laryngeal or pharyngeal sensitivity ${ }^{100,101}$.

Dysphagia is an important cause of dehydration and malnutrition in MS patients leading to a high mortality rate $^{100}$.

Swallowing alterations in MS patients can be evaluated through patient's history, bedside screening examination, fiberoptic endoscopic evaluation of swallowing to evaluate the buccal and pharyngo-laryngeal phases and video-fluoroscopy ${ }^{101}$. Self-administered questionnaires, such as the DYMUS (Dysphagia in Multiple Sclerosis) questionnaire, have also been proposed to evaluate symptom progression ${ }^{97}$.

Electromyography should be performed before treatment to identify the affected muscles and better address treatment with botulin toxin alone ${ }^{102}$ or associated with physical rehabilitation ${ }^{103}$. Alfonsi et al. showed that $92 \%$ of patients in the later stage of MS presented prolonged electromyographic activity of suprahyoid/ submental muscle (buccal phase) and an increased time in the laryngo-pharyngeal phase ${ }^{104}$, suggesting to add electromyography to the diagnostic exams to define treatment.

\section{Speech disorders}

Nearly $40 \%$ of subjects with a diagnosis of MS have speech disorders such as dysphonia and dysarthria and, at a lesser extent, comprehension disorders ${ }^{105,106}$.

Dysphonia in MS may follow alteration of the vocal fold control and in voice production ${ }^{107}$; symptoms include hoarseness and poor control of volume and pitch ${ }^{108}$. Transitory spasms of vocal fold may induce sudden and temporary interruptions of voice ${ }^{109}$. Dysarthria is predominantly a mixed form with ataxic and spastic speech characteristics ${ }^{110}$, typically scanning speech.

Dysphonia is more common in the early stage of MS and in some cases it may be a presenting symptom of $\mathrm{MS}^{109}$; it may appear as a transitory hypofunctional dysphonia that recovery spontaneously after $15-20$ days ${ }^{107}$, or as an episode of spastic dysphonia without evidence of laryngeal pharyngeal reflux ${ }^{109,111}$. Dysarthria is more common during the late stage of MS.

Both dysphonia and dysarthria may be correlated to an alteration of the expiratory and phonatory times ${ }^{112}$. Nordio et al. showed that a reduction of the expiratory and phonatory time in patients with MS was directly correlated with the increase of the Expanded Disability Status Scale (EDSS) score ${ }^{112}$, reporting more speech difficulties during the relapsing phases of MS and suggesting that they may be correlated to the severity of the speech disorder ${ }^{109,112}$.

Speech disorders are mainly correlated to demyelinating lesions in the central speech pathways rather than to a peripheral involvement of recurrent nerve ${ }^{107}$; in particular, these disorders may be observed in case of lesions located in the subthalamic regions ${ }^{113}$ and in the periaqueductal area $^{108}$. They mainly follow a progressive weakness of the musculature that can involve all the speech mechanisms and provoke a relevant decrease of verbal communication skills. The "fatigue" component is extremely relevant in the expiration mechanism and the stiffness that affects muscle involved in speech production and emission may further worsen speech ${ }^{112}$.

Speech disorders in patient with MS may be investigated with perceptual, acoustic, aerodynamic, and physiological assessments though computer or laboratory-based practices ${ }^{114}$. Specifically, voice characteristic can be evaluated with the Multi-Dimensional Voice Program (MDVP) ${ }^{115}$, electroglottography ${ }^{116}$ and videostroboscopy ${ }^{117}$. These methods can measure phonation instability ${ }^{108}$, alterations of voice parameters in specific frequency bands, jitter, and shimmer ${ }^{118}$ by offering a detailed investigation of voice features ${ }^{119}$.

Many studies have revealed that an early treatment of MS and a speech rehabilitation therapy in MS patients with speech disorders can significantly help in controlling the progressive alteration in the intelligibility of the speech capacity ${ }^{120-122}$.

\section{Sleep disorders}

Sleep Disorders (SD), including Obstructive Sleep Apnea (OSA) and Central Sleep Apnea (CSA), are significantly underestimated comorbidities in patients with $\mathrm{MS}^{123}$ with a significant worsening of quality of life ${ }^{124}$. SD may worsen fatigue, common in patients with $\mathrm{MS}^{125,126}$; however, the extent to which OSA and CSA contribute to these symptoms remains unclear ${ }^{127,128}$.

There may be significant bidirectional relationships between SD and MS. Previous studies have demonstrated that the prevalence and severity of $S D$ are higher in persons with $\mathrm{MS}^{129,130}$. Furthermore, it has been demonstrated that among patients with MS, OSA and SD are significantly 
associated with diminished visual memory, verbal memory, executive function, attention, processing speed, and working memory ${ }^{131}$.

The lesions involving the brainstem and the spinal cord could alter breathing control and upper airway muscle activity. The physiological respiration rate and synchronism during the night comprehends an increase of the pharyngeal tone; the tone is strongly hold due to the coordination between the palatal and genioglossus muscles and the action of the $X$ and XII cranial nerves ${ }^{132,133}$. In some MS patients, lesions can alter the equilibrium of afferent nerves and chemoreceptors, resulting in OSA. Simultaneously, intermittent hypoxia could increase oxidative stress and, combined with alterations in hypocapnia sensitivity thresholds, may worsen neurodegeneration in patients with MS, leading to $\mathrm{CSA}^{134,135}$. The main cause lies on alterations in the brainstem, which often occur in the late stage of the disease $^{123}$. Braley et al. evaluated apnea-hypopnea and central apnea indices in 48 patients with MS compared to 48 controls showing significantly worse results among MS patients, and suggesting a predisposition for OSA and CSA among patients with MS, particularly among those with brainstem involvement ${ }^{136}$.

Diagnosis and assessment of SD can be done using polysomnography ${ }^{137}$. Continuous positive airway pressure has been shown to play a significant role in OSA and especially-CSA in MS patients ${ }^{138}$.

\section{CONCLUSION}

Otolaryngologic symptoms are common in MS; however, they are often overlooked. They can appear either during the early stage of the disease, in some cases being the presenting symptoms of MS, or at a later stage. Sometimes they can even precede the evidence of the lesions at the MRI, as reported for sudden SNHL and facial palsy. Many of these symptoms significantly affect the quality of life or patients and lead to increased morbidity and mortality.

In many cases, otolaryngologic symptoms follow the relapsing-remitting phases of the disease, and may spontaneously disappear, leading to a delay in MS diagnosis when the condition is still undiagnosed. Furthermore, the common use of corticosteroids to treat these symptoms regardless their origin often results in a regression or resolution of the symptom; however, this may also delay the diagnosis of MS.

It would be recommended for clinicians involved with the diagnosis and therapy of these symptoms to also consider MS as a possible cause, especially when associated to neurologic symptoms, as they may provide further clinical suspect of a central condition. Furthermore, a better knowledge of the otolaryngologic symptoms of MS is auspicial among otolaryngologists, audiologists and phoniatricians as this could help considering MS as an etiologic factor in these patients. Last, neurologists should consider the role of the otolaryngologist in the clinical management of patients with MS to help identifying symptoms indicative of disease progression.

\section{REFERENCES}

1. Reich DS, Lucchinetti CF, Calabresi PA. Multiple sclerosis. N Engl J Med. 2018;378(2):169-80.

2. Howard J, Trevick S, Younger DS, Epidemiology of Multiple Sclerosis. Neurol Clin. 2016;34(4):919-39.

3. Stys PK. Multiple sclerosis: autoimmune disease or autoimmune reaction? Can J Neurol Sci. 2010;37(2):16-23.

4. Kami $\square$ ska J, Koper OM, Piechal K, Kemona H. Multiple sclerosis - etiology and diagnostic potential. Postepy Hig Med Dosw. 2017;71(0):551-63.

5. Yadav SK, Mindur JE, Ito K, Dhib-Jalbut S. Advances in the immunopathogenesis of multiple sclerosis. Curr Opin Neurol. 2015;28(3):206-19.

6. Liutkeviciene R, Vilkeviciute A, Banevicus M, Miežyte R, Kriauciuniene L. Association of MMP-2(-1306 C/T) gene polymorphism with predisposition to optic neuritis and optic neuritis together with multiple sclerosis. Medicina. 2018;54(2):29.

7. Xia Z, White CC, Owen EK, Korff AV, Clarkson SR, McCabe CA, et al. Genes and environment in multiple sclerosis project: A platform to investigate multiple sclerosis risk. Ann Neurol. 2016;79(2):178-89.

8. Bhargava P, Mowry EM. Gut microbiome and multiple sclerosis. Curr Neurol Neurosci Rep. 2014;14(10):492.

9. Luo C, Jian C, Liao Y, Huang Qi, Wu Y, Liu X, et al. The role of microglia in multiple sclerosis. Neuropsychiatr Dis Treat. 2017;13:1661-7.

10. Garg N, Smith TW. An update on immunopathogenesis, diagnosis, and treatment of multiple sclerosis. Brain Behav. 2015;5(9):e00362.

11. Brownlee WJ, Hardy TA, Fazekas F, Miller DH. Diagnosis of multiple sclerosis: progress and challenges. Lancet. 2017;389(10076):133646.

12. Rolak LA. Multiple sclerosis: it's not the disease you thought it was Clin Med Res. 2003;1(1):57-60.

13. Bogie JF, Stinissen P, Hendriks JJ. Macrophage subsets and microglia in multiple sclerosis. Acta Neuropathol. 2014;128(2):191-213.

14. Di Stadio A, Ralli M. Inner ear involvement in multiple sclerosis: An underestimated condition? Mult Scler. 2018;24(9):1264-65.

15. O'Malley JT, Nadol JB Jr, McKenna MJ. Anti CD163+, Iba1+, and CD68 + Cells in the adult human inner ear: normal distribution of an unappreciated class of macrophages/microglia and implications for inflammatory otopathology in humans. Otol Neurotol. 2016;37(1):99108

16. Di Stadio A, Dipietro L, Ralli M, Meneghello F, Minni A, Greco A, et al. Sudden hearing loss as an early detector of multiple sclerosis: a systematic review. Eur Rev Med Pharmacol Sci. 2018;22(14):4611-24.

17. Atula S, Sinkkonen ST, Saat R, Sairanen T, Atula T. Association of multiple sclerosis and sudden sensorineural hearing loss. Mult Scler J Exp Transl Clin. 2016;2:2055217316652155.

18. Hellmann MA, Steiner I, Mosberg-Galili R. Sudden sensorineural hearing loss in multiple sclerosis: clinical course and possible pathogenesis. Acta Neurol Scand. 2011;124(4):245-9.

19. Furst M, Levine RA. Hearing disorders in multiple sclerosis. Handb Clin Neurol. 2015;129:649-65.

20. Daugherty WT, Lederman RJ, Nodar RH, Conomy JP. Hearing loss in multiple sclerosis. Arch Neurol. 1983;40(1):33-5.

21. Ralli M, D’Aguanno V, Di Stadio A, De Virgilio A, Croce A, Longo L, et al. Audiovestibular symptoms in systemic autoimmune diseases. J Immunol Res. 2018;p:5798103. 
22. Alexander TH, Harris JP. Incidence of sudden sensorineural hearing loss. Otol Neurotol. 2013;34(9):1586-9.

23. Baguley D, McFerran D, HallD. Tinnitus. Lancet.2013;382(9904):16007.

24. Ferreira LM, Ramos AN, Mendes EP. Characterization of tinnitus in the elderly and its possible related disorders. Braz J Otorhinolaryngol. 2009;75(2):249-55.

25. Salvi RD, Jiang D, Chen H, Greco GD, Manohar A, Sun S, et al. Agerelated hearing loss and hearing disorders: current knowledge and future directions. Hearing Balance Commun. 2018;16(1):1-9.

26. Ralli M, Balla MP, Greco A, Altissimi G, Ricci P, Turchetta R, et al. Work-related noise exposure in a cohort of patients with chronic tinnitus: analysis of demographic and audiological characteristics. Int J Environ Res Public Health. 2017;14(9)

27. Di Stadio A, Dipietro L, Ricci G, Della Volpe A, Minni A, Greco A, et al. Hearing loss, tinnitus, hyperacusis, and diplacusis in professional musicians: A systematic review. Int J Environ Res Public Health. 2018;15(10).

28. Roberts LE, Eggermont JJ, Caspary DM, Shore SE, Melcher JR, Kaltenbach JA, et al. Ringing ears: The neuroscience of tinnitus. $J$ Neurosci. 2010;30(45): 14972-9.

29. Ralli M, Di Stadio A, Greco A, Altissimi G, Mazzei F, Turchetta R, et al. Development of progressive hearing loss and tinnitus in a patient with myasthenia gravis: an overlooked comorbidity? Hearing Balance Commun. 2017:1-7.

30. Kujawa SG, Liberman MC. Synaptopathy in the noise-exposed and aging cochlea: Primary neural degeneration in acquired sensorineural hearing loss. Hear Res. 2015;330(Pt B):191-9.

31. Liberman MC, Kujawa SG. Cochlear synaptopathy in acquired sensorineural hearing loss: Manifestations and mechanisms. Hear Res. 2017;349:138-147.

32. Shore S, Zhou J, Koehler S. Neural mechanisms underlying somatic tinnitus. Prog Brain Res. 2007;166:107-23.

33. Shore SE, Roberts LE, Langguth B. Maladaptive plasticity in tinnitus-triggers, mechanisms and treatment. Nat Rev Neurol. 2016;12(3):150-60.

34. Ralli M, Altissimi G, Turchetta R, Mazzei F, Salviati M, Cianfrone F, et al. Somatosensory tinnitus: Correlation between cranio-cervicomandibular disorder history and somatic modulation. Audiol Neurootol. 2016;21(6):372-382.

35. Ralli M, Greco A, Boccassini A, Altissimi G, Di Paolo C, Falasca $\mathrm{V}$, et al. Subtyping patients with somatic tinnitus: Modulation of tinnitus and history for somatic dysfunction help identify tinnitus patients with temporomandibular joint disorders. PLoS One. 2018;13(8):e0202050.

36. Ralli M, Greco A, Cialente F, Di Stadio A, de Virgilio A, Longo L, et al. Somatic tinnitus. Int Tinnitus J. 2017;21(2):112-121.

37. Ralli M, Greco A, Turchetta R, Altissimi G, de Vincentiis M, Cianfrone $G$, et al. Somatosensory tinnitus: Current evidence and future perspectives. J Int Med Res. 2017;45:933-947.

38. Langguth B, Kreuzer PM, Kleinjung T, De Ridder D. Tinnitus: Causes and clinical management. Lancet Neurol. 2013;12(9):920-30.

39. Mancini P, Atturo F, Di Mario A, Portanova G, Ralli M, De Virgilio $A$, et al. Hearing loss in autoimmune disorders: Prevalence and therapeutic options. Autoimmun Rev. 2018;17(7):644-652.

40. Ralli M, Greco A, De Vincentiis M, Sheppard A, Cappelli G, Neri I, et al. Tone-in-noise detection deficits in elderly patients with clinically normal hearing. Am J Otolaryngol. 2018;S0196-0709(18):30750-6.

41. Bodling AM, DR Denney, SG Lynch. Individual variability in speed of information processing: an index of cognitive impairment in multiple sclerosis. Neuropsychology. 2012;26(3):357-67.
42. Lewis MS, Lilly DJ, Hutter M, Bourdette DN, Saunders J, Fausti SA. Some effects of multiple sclerosis on speech perception in noise: Preliminary findings. J Rehabil Res Dev. 2006;43(1):91-8.

43. Valadbeigi A, Weisi F, Rohbakhsh N, Rezaei M, Heidari A, Rasa AR. Central auditory processing and word discrimination in patients with multiple sclerosis. Eur Arch Otorhinolaryngol. 2014;271(11):2891-6.

44. Grzegorski T, Losy J. Cognitive impairment in multiple sclerosis a review of current knowledge and recent research. Rev Neurosci. 2017;28(8):845-860.

45. Kaytanci E, Ozdamar OI, Acar GO, Tekin M. Evaluation of transiently evoked otoacoustic emissions and auditory brainstem responses in patients with multiple sclerosis. Ear Nose Throat $\mathrm{J}$. 2016;95(10-11):E12-E17.

46. Mostafa BE, Kahky AO, Kader HM, Rizk M. Central vestibular dysfunction in an otorhinolaryngological vestibular unit: incidence and diagnostic strategy. Int Arch Otorhinolaryngol. 2014;18(3):2358.

47. Russo FY, Ralli M, De Seta D, Mancini P, Lambiase A, Artico M, et al. Autoimmune vertigo: an update on vestibular disorders associated with autoimmune mechanisms. Immunol Res. 2018.

48. Pula JH, Newman-Toker DE, Kattah JC. Multiple sclerosis as a cause of the acute vestibular syndrome. J Neurol. 2013;260(6):1649-54.

49. Marrie RA, Cutter GR, Tyry T. Substantial burden of dizziness in multiple sclerosis. Mult Scler Relat Disord. 2013; 2(1):21-8.

50. Magliulo G, lannella G, Manno A, Libonati L, Onesti E, Vestri A, et al. Chronic inflammatory demyelinating polyneuropathy: evaluation of the vestibular system with cervical and ocular vestibular evoked myogenic potentials. Eur Arch Otorhinolaryngol. 2018;275(6):15071512.

51. Ferber-Viart C, Dubreuil C, Duclaux R, Vestibular evoked myogenic potentials in humans: a review. Acta Otolaryngol. 1999;119(1):6-15.

52. Hoh AE, Beisse C. Oculomotor system and multiple sclerosis. Ophthalmologe. 2014;111(8):727-32.

53. Alpini D, Caputo D, Pugnetti L, Giuliano DA, Cesarani A. Vertigo and multiple sclerosis: aspects of differential diagnosis. Neurol Sci. 2001;S84-7.

54. TamasTL, Garai T, Tompos T, Szirmai Á. Vertigo in the Emergency Department: new bedside tests. Orv Hetil. 2016;157(11):403-9.

55. Fukazawa T, Moriwaka F, Hamada K, Hamada T, Tashiro K. Facial palsy in multiple sclerosis. J Neurol. 1997;244(10):631-3.

56. Critchley EP. Multiple sclerosis initially presenting as facial palsy. Aviat Space Environ Med. 2004;75(11):1001-4.

57. Topolska MM, Kulak W. Facial palsy as the first syndrome of multiple sclerosis in 16 years old girl. Otolaryngol Pol. 2006;60(3):439-42.

58. Di Stadio A, Bernitsas E. The origin of facial palsy in multiple sclerosis. Otolaryngol Open J. 2018;4(1):1-4.

59. Adeva-Bartolome MT, Blazquez-Estrada MT, Fermoso-Garcia J. Bell's palsy as a form of presentation of multiple sclerosis. Rev Neurol. 1999;28(5):534.

60. Kwon JY, Kim JY, Jeong JH, Park KD. Multiple sclerosis and peripheral multifocal demyelinating neuropathies occurring in a same patient. J Clin Neurol. 2008;4(1):51-7.

61. Greco A, Gallo A, Fusconi M, Marinelli C, Macri GF, de Vincentiis M. Bell's palsy and autoimmunity. Autoimmun Rev. 2012;12(2):323-8.

62. Saleh C, Patsi O, Mataigne F, Beyenburga S. Peripheral (seventh) nerve palsy and multiple sclerosis: A diagnostic dilemma - a case report. Case Rep Neurol. 2016;8(1):27-33.

63. Gallud L, Began JV, CervellO A, Jimenez Y, Poveda R, Gavalda C. Multiple sclerosis as first manifestation in oral and facial area: presentation of four cases. Med Oral Patol Oral Cir Bucal. 2006;11(2):E141-5. 
64. Hooge JP, Redekop WK. Trigeminal neuralgia in multiple sclerosis. Neurology. 1995;45(7):1294-6.

65. Commins DJ, Chen JM. Multiple sclerosis: a consideration in acute cranial nerve palsies. Am J Otol. 1997;18(5):590-5.

66. Chemaly D, Lefrancois A, Perusse R. Oral and maxillofacial manifestations of multiple sclerosis. J Can Dent Assoc. 2000;66(11):600-5.

67. Hartmann M, Rottach KG, Wohlgemuth WA, Pfadenhauer K. Trigeminal neuralgia triggered by auditory stimuli in multiple sclerosis. Arch Neurol. 1999;56(6):731-3.

68. Flint S, Scully C. Isolated trigeminal sensory neuropathy: a heterogeneous group of disorders. Oral Surg Oral Med Oral Pathol. 1990;69(2):153-6.

69. Penarrocha Diago M, Bagán Sebastián JV, Giner AA, Orenga VE. Mental nerve neuropathy in systemic cancer. Report of three cases. Oral Surg Oral Med Oral Pathol. 1990;69(1):48-51.

70. Broggi G, Ferroli P, Franzini A, Nazzi V, Farina L, La Mantia L, et al. Operative findings and outcomes of microvascular decompression for trigeminal neuralgia in 35 patients affected by multiple sclerosis. Neurosurgery. 2004;55(4):830-8.

71. Nakashima I, Fujihara K, Kimpara T, Okita N, Takase S, Itoyama Y. Linear pontine trigeminal root lesions in multiple sclerosis: clinical and magnetic resonance imaging studies in 5 cases. Arch Neurol. 2001;58(1):101-4.

72. Muzyka IM, Estephan B. Electrophysiology of cranial nerve testing: Trigeminal and facial nerves. J Clin Neurophysiol. 2018;35(1):16-24.

73. Zakrzewska JM, Wu J, Brathwaite TS. A systematic review of the management of trigeminal neuralgia in patients with multiple sclerosis. World Neurosurg. 2018;111:291-306.

74. Ciurleo R, Bonanno L, De Salvo S, Romeo L, Rifici C, Sessa E, et al. Olfactory dysfunction as a prognostic marker for disability progression in Multiple Sclerosis: An olfactory event related potential study. PLoS One. 2018;13(4):e0196006.

75. Doty RL, Mannon LJ, Yousem DM. Olfactory dysfunction in multiple sclerosis. Relation to plaque load in inferior frontal and temporal lobes. Ann N Y Acad Sci. 1998;855:781-6.

76. Hawkes $\mathrm{CH}$, Shephard BC. Olfactory evoked responses and identification tests in neurological disease. Ann $N$ Y Acad Sci. 1998;855:608-15.

77. Lucassen EB, Turel A, Knehans A, Huang X, Eslinger P. Olfactory dysfunction in multiple sclerosis: A scoping review of the literature. Mult Scler Relat Disord. 2016;6:1-9.

78. Lutterotti A, Turel A, Knehans A, Huang X, Eslinger P. Olfactory threshold is impaired in early, active multiple sclerosis. Mult Scler. 2011;17(8):964-9.

79. Pimentel ML. Olfactory dysfunction as a marker of multiple sclerosis progression. Arq Neuropsiquiatr. 2016;74(9):693-4.

80. Fleiner F, Dahlslett SB, Schmidt F, Harms L, Goektas O. Olfactory and gustatory function in patients with multiple sclerosis. Am J Rhinol Allergy. 2010; 24(5):e93-7.

81. Silva AM, Santos E, Moreira I, Bettencourt A, Coutinho E, Gonçalves $A$, et al. Olfactory dysfunction in multiple sclerosis: association with secondary progression. Mult Scler. 2012;18(5):616-21.

82. Bsteh G, Hegen H, Ladstätter F, Berek K, Amprosi M, Wurth S, et al. Change of olfactory function as a marker of inflammatory activity and disability progression in MS. Mult Scler. 2017;1352458517745724.

83. Zorzon M, Ukmar M, Bragadin LM, Zanier F, Antonello RM, Cazzato $G$, et al. Olfactory dysfunction and extent of white matter abnormalities in multiple sclerosis: a clinical and MR study. Mult Scler. 2000;6(6):386-90.

84. Shin T, Kim J, Ahn M, Moon C. Olfactory dysfunction in CNS neuroimmunological disorders: A review. Mol Neurobiol. 2018;p:1-8.
85. Hashimoto T, Doden T, Ono Y, Uematsu T. Bilateral hypogeusia caused by a small lesion in the lower midbrain tegmentum. BMJ Case Rep. 2012.

86. Combaross O, Juan SP, Berciano J, Pablos C. Hemiageusia from an ipsilateral multiple sclerosis plaque at the midpontine tegmentum. $J$ Neurol Neurosurg Psychiatry. 2000;68(6):796.

87. Naik C, Claussen CF. Qualitative and quantitative representation of taste disturbances: how we do it by pentagon chart. Indian J Otolaryngol Head Neck Surg. 2010;62(4):376-80.

88. Doty RL, Tourbier IA, Pham DL, Cuzzocreo JL, Udupa JK, Karacali B, et al. Taste dysfunction in multiple sclerosis. J Neurol. 2016;263(4):677-88.

89. Lakraj AA, Moghimi N, Jabbari B. Sialorrhea: anatomy, pathophysiology and treatment with emphasis on the role of botulinum toxins. Toxins (Basel). 2013;5(5):1010-31.

90. McGeachan AJ, McDermott CJ. Management of oral secretions in neurological disease. Pract Neurol. 2017;17(2):96-103.

91. Squires NA Wills, Rowson J. The management of drooling in adults with neurological conditions. Curr Opin Otolaryngol Head Neck Surg. 2012;20(3):171-6.

92. Vashishta R, Nguyen SA, White DR, Gillespie MB. Botulinum toxin for the treatment of sialorrhea: a meta-analysis. Otolaryngol Head Neck Surg. 2013;148(2):191-6.

93. Habek M, Karni A, Balash Y, Gurevich T. The place of the botulinum toxin in the management of multiple sclerosis. Clin Neurol Neurosurg. 2010;112(7):592-6.

94. Safarpour Y, Mousavi T, Jabbari B. Botulinum toxin treatment in multiple sclerosis: a review. Curr Treat Options Neurol. 2017; 19(10):33

95. Rius JM, Llobet LB, Soler EL, Farré M. salivary secretory disorders, inducing drugs, and clinical management. Int $\mathrm{J}$ Med Sci. 2015;12(10):811-24.

96. Tassorelli C, Bergamaschi R, Buscone S, Bartolo M, Furnari A, Crivelli $P$, et al. Dysphagia in multiple sclerosis: from pathogenesis to diagnosis. Neurol Sci. 2008;29(4):S360-3.

97. Solaro C, Rezzani C, Trabucco E, Amato MP, Zipoli V, Portaccio $\mathrm{E}$, et al. Prevalence of patient-reported dysphagia in multiple sclerosis patients: an Italian multicenter study (using the DYMUS questionnaire). J Neurol Sci. 2013;331(1-2):94-7.

98. Calcagno P, Ruoppolo G, Grasso MG, De Vincentiis M, Paolucci S. Dysphagia in multiple sclerosis-prevalence and prognostic factors. Acta Neurol Scand. 2002;105(1):40-3.

99. Alali $\mathrm{D}$, Ballard $\mathrm{K}$, Bogaardt $\mathrm{H}$. The frequency of dysphagia and its impact on adults with multiple sclerosis based on patient-reported questionnaires. Mult Scler Relat Disord. 2018;25:227-231.

100. De Pauw A, Dejaeger E, D'hooghe B, Carton H. Dysphagia in multiple sclerosis. Clin Neurol Neurosurg. 2002;104(4):345-51.

101. Prosiegel M, Schelling A, Wagner-Sonntag E. Dysphagia and multiple sclerosis. Int MS J. 2004;11(1): 22-31.

102. Restivo DA, Marchese-Ragona R, Patti F, Solaro C, Maimone D, Zappalá G, et al. Botulinum toxin improves dysphagia associated with multiple sclerosis. Eur J Neurol. 2011;18(3):486-90.

103. Rommer PS, Eichstädt K, Ellenberger D, Flachenecker P, Friede $\mathrm{T}$, Haas $\mathrm{J}$, et al. Symptomatology and symptomatic treatment in multiple sclerosis: Results from a nationwide MS registry. Mult Scler. 2018; 1352458518799580.

104. Alfonsi E, Bergamaschi R, Cosentino G, Ponzio M, Montomoli C, Restivo DA, et al. Electrophysiological patterns of oropharyngeal swallowing in multiple sclerosis. Clin Neurophysiol. 2013;124(8):1638-45.

105. Fazeli M, Moradi N, Soltani M, Naderifar E, Majdinasab N, Latifi SM, 
et al. Dysphonia characteristics and vowel impairment in relation to neurological status in patients with multiple sclerosis. J Voice. 2018.

106. Noffs G, Perera T, Kolbe SC, Shanahan CJ, Boonstra FMC, Evans A, et al. What speech can tell us: A systematic review of dysarthria characteristics in Multiple Sclerosis. Autoimmun Rev. 2018; 17(12):1202-1209.

107. Renauld S, Mohamed-Said L, Macoir J. Language disorders in multiple sclerosis: A systematic review. Mult Scler Relat Disord. 2016;10:103-111.

108. Hartelius L, Buder EH, Strand EA. Long-term phonatory instability in individuals with multiple sclerosis. J Speech Lang Hear Res. 1997;40(5):1056-72.

109. Di Stadio A, Bernitsas E, Restivo DA, Alfonsi E, Marchese-Ragona R. Spasmodic dysphonia in multiple sclerosis treatment with botulin toxin A: A pilot study. J Voice. 2018

110. Yamout B, Fuleihan N, Hajj T, Sibai A, Sabra O, Rifai $H$, et al. Vocal symptoms and acoustic changes in relation to the expanded disability status scale, duration and stage of disease in patients with multiple sclerosis. Eur Arch Otorhinolaryngol. 2009;266(11):1759-65.

111. Monini S, Di Stadio A, Vestri A, Barbara M. Silent reflux: ex juvantibus criteria for diagnosis and treatment of laryngeal disorders. Acta Otolaryngol. 2006. 126(8):866-71.

112. Nordio S, Bernitsas E, Meneghello F, Palmer K, Stabile MR, Dipietro $\mathrm{L}$, et al. Expiratory and phonation times as measures of disease severity in patients with Multiple Sclerosis. A case-control study. Mult Scler Relat Disord. 2018;23:27-32

113. Hintze JM, Ludlow CL, Bansberg SF, Adler CH, Lott DG. Spasmodic dysphonia: A review. Part 2: Characterization of pathophysiology. Otolaryngol Head Neck Surg. 2017;157(4):558-564.

114. Rusz J, Benova B, Ruzickova H, Novotny M, Tykalova T, Hlavnicka $J$, et al. Characteristics of motor speech phenotypes in multiple sclerosis. Mult Scler Relat Disord. 2018;19:62-69.

115. Pützer M, Barry WJ, Moringlane JR, Fuss G, Spiegel J, Dillmann $U$, et al. Effect of deep brain stimulation on glottal phonation in patients with Parkinson's disease and multiple sclerosis. Folia Phoniatr Logop. 2003;55(5):220-32

116. Konstantopoulos K, Vikelis M, Seikel JA, Mitsikostas DD. The existence of phonatory instability in multiple sclerosis: an acoustic and electroglottographic study. Neurol Sci. 2010;31(3):259-68.

117. Dogan M, Midi I, Yazici MA, Kocak I, Günal D, Sehitoglu MA. Objective and subjective evaluation of voice quality in multiple sclerosis. J Voice. 2007;21(6):735-40.

118. Feijo AV, Parente MA, Behlau M, Haussen S, De Veccino MC, Martignago BC, et al. Acoustic analysis of voice in multiple sclerosis patients. J Voice. 2004;18(3):341-7.

119. Yamout B, Al-Zaghal Z, El-Dahouk I, Farhat S, Sibai A, Hamdan AL. Mean contact quotient using electroglottography in patients with multiple sclerosis. J Voice. 2013;27(4):506-11.

120. Goodwin SJ, Carpenter AF. Successful treatment of paroxysmal ataxia and dysarthria in multiple sclerosis with levetiracetam. Mult Scler Relat Disord. 2016;10:79-81.
121. Pepping $M$, Brunings J, Goldberg $M$. Cognition, cognitive dysfunction, and cognitive rehabilitation in multiple sclerosis. Phys Med Rehabil Clin N Am. 2013;24(4):663-72.

122. Scheinberg L, Smith CR (1987) Rehabilitation of patients with multiple sclerosis. Neurol Clin. 1987;5(4):585-600.

123. Hensen HA, Krishnan AV, Eckert DJ. Sleep-disordered breathing in people with multiple sclerosis: Prevalence, pathophysiological mechanisms, and disease consequences. Front Neurol. 2017;8:740.

124. Veauthier C, Gaede G, Radbruch H, Wernecke KD, Paul F. Sleep disorders reduce health-related quality of life in multiple sclerosis (nottingham health profile data in patients with multiple sclerosis). Int J Mol Sci. 2015;16(7):16514-28.

125. Kaminska M, Kimoff RJ, Benedetti A, Robinson A, Bar-Or A, Lapierre $\mathrm{Y}$, et al. Obstructive sleep apnea is associated with fatigue in multiple sclerosis. Mult Scler. 2012;18(8):1159-69.

126. Braley TJ, Segal BM, Chervin RD. Obstructive sleep apnea and fatigue in patients with multiple sclerosis. J Clin Sleep Med. 2014;10(2):155-62.

127. Leonavicius R, Adomaitiene V. Features of sleep disturbances in multiple sclerosis patients. Psychiatr Danub. 2014;26(3):249-55.

128. Carnická Z, Kollár B, Šiarnik P, Krížová L, Klobučníková K. Sleep disorders in patients with multiple sclerosis. J Clin Sleep Med. 2015;11(5):553-7.

129. Veauthier C, Radbruch H, Gaede G, Pfueller CF, Dörr J, BellmannStrobl $\mathrm{J}$, et al. Fatigue in multiple sclerosis is closely related to sleep disorders: a polysomnographic cross-sectional study. Mult Scler. 2011;17(5):613-22.

130. Tachibana N, Howard RS, Hirsch NP, Miller DH, Moseley IF, Fish D. Sleep problems in multiple sclerosis. Eur Neurol. 1994;34(6):320-3.

131. Braley TJ, Kratz AL, Kaplish N, Chervin RD. Sleep and Cognitive Function in Multiple Sclerosis. Sleep. 2016;39(8):1525-33.

132. White DP. Advanced Concepts in the pathophysiology of obstructive sleep apnea. Adv Otorhinolaryngol. 2017;80:7-16.

133. Jordan AS, McSharry DG, Malhotra A. Adult obstructive sleep apnoea. Lancet. 2014;383(9918):736-47.

134. Salloum A, Rowley JA, Mateika JH, Chowdhuri S, Omran Q, Badr MS. Increased propensity for central apnea in patients with obstructive sleep apnea: effect of nasal continuous positive airway pressure. Am J Respir Crit Care Med. 2010;181(2):189-93.

135. Steffen A. Central sleep apnea in multiple sclerosis. HNO. 2010;58(4):405-8.

136. Braley TJ, Segal BM, Chervin RD. Sleep-disordered breathing in multiple sclerosis. Neurology. 2012;79(9):929-36.

137. Chen JH, Liu XQ, Sun HY, Huang Y. Sleep disorders in multiple sclerosis in China: clinical, polysomnography study, and review of the literature. J Clin Neurophysiol. 2014;31(4):375-81.

138. Dernaika T, Tawk M, Nazir S, Younis W, Kinasewitz GT. The significance and outcome of continuous positive airway pressurerelated central sleep apnea during split-night sleep studies. Chest. 2007;132(1):81-7. 